\title{
Civilisations
}

Revue internationale d'anthropologie et de sciences

humaines

44 | 1997

Les peuples des forêts tropicales

\section{Shifting cultivation in the Ituri Forest [Haut-Zaïre]}

Colonial intervention, present situation, economic and ecological prospects

\section{Michael Rösler}

\section{OpenEdition}

\section{Journals}

Electronic version

URL: http://journals.openedition.org/civilisations/1608

DOI: 10.4000/civilisations. 1608

ISSN: 2032-0442

\section{Publisher}

Institut de sociologie de l'Université Libre de Bruxelles

\section{Printed version}

Date of publication: 1 January 1997

Number of pages: $44-61$

ISBN: 2-87263-122-4

ISSN: 0009-8140

Electronic reference

Michael Rösler, "Shifting cultivation in the Ituri Forest [Haut-Zaïre] », Civilisations [Online], 44 | 1997, Online since 29 June 2009, connection on 07 May 2019. URL : http://journals.openedition.org/ civilisations/1608; DOI : 10.4000/civilisations.1608 
-

\section{SHHFINGG CULTVYHTION IN THE ITURF FOREST}

[HAUT-ZHARE]

colonial intervention, present situdition, economic and ecological prospectsm

Michael RÖSLER 


\section{|NDROOUCTION}

The study of shifting cultivation in the Central African rain forest has rarely been made the subject of anthropological research. One can only speculate upon the reasons for this reluctance. Maybe there is a general awareness of the conceptual complications brought about by colonial intervention and its impact on local agrarian systems [Miracle, 1967]. If the colonial context is fully taken into account, long-standing anthropological paradigms are threatened indeed. The Ituri Forest of North Eastern Zaire is a particular case in point. Until now, anthropologists have restricted their efforts to groups of so-called huntergatherers; one fancies Pygmies as one of the last exotic peoples of the world apparently representing the earliest stages of human evolution. As a consequence of this rather naive and romantic view, the village-dwelling agricultural people, who represent the majority of the population in the Ituri Forest, have been completely neglected. After Tumbull's $(1965,1983)$ verdict that there is an insurmountable contrast between "village world" and "forest world", nobody has dared to take up the "villager's point of view". The banishment of the agriculturalists, by being characterized as heing essentially a non-forest population who immigrated only recently and destroyed the forest by shifting cultivation, created a powerful anthropological myth that led to erronious interpretations not only of the cultivators but also of the socio-economic status of the Pygmies as hunter-gatherers in the overall local economy.

Such assumptions underlying hunter-gatherer research in the Ituri have been questioned only recently. Thus ecologists doubt that the forest provides the necessary carbohydrate resources to support independent hunter-gatherers [Hart and Hart, 1986, Bailey and Headland, 1991]. For the first time it is fully recognized that Pygmy foragers like the Efe are heavily dependent on their l.ese agricultural neighbours, with whom they maintain close economic and social relations [Bailey and Peacock, 1988]. Although agriculture is currently receiving special attention, some misconceptions on its apparent static and unchanging nature still prevail. Going a step further and hypothesizing that today's agriculture in the Ituri forest, far from being traditional, is a product of former colonial development measures, one can conclude that the celebrated opposition of village and forest world represents the functional differentiation of agriculture and hunting-gathering as separate, albeit interdependent, economic systems which came into being only under colonial rule. The current system of shifting cultivation can best be described as neo-traditional, composed of modern (colonial) and traditional (precolonial) structural elements. It is a locally adapted version of what was introduced by the Belgian Colonial Administration into the Ituri Forest under the heading of paysannat indigene including resettlement schemes and compulsory cultivation LJurion and Henry 1967].

If far-reaching measures like this are taken into account, it becomes clear that it is much less the traditional than the transitional aspects of the Ituri societies that come to the fore. This paper will discuss the major ethnological, economic, and developmental implications of this perspective "from the villager's point of view" (2]. It attempts to reconstruct pre-colonial agriculture, 



ruled the Chefferie des Bombo from 1930-48. This time span is identified as an epoch of glory full of heroic deeds. One of them is the construction of a $60 \mathrm{~km}$ roadway south of the Ituri, that was initiated by Kayumba, after the population was forced into villages along the major road that crosses the Ituri Forest from west to east. This saved the southern Bombo communities from being evicted from their ancestral territories on the bank of the lenda river. Nevertheless, compulsory cultivation of cotton, reaching its zenith in the fifties, could not be averted. The western Ituri Forest became part of the zone cotonniere Nord and was subjected to experimental paysannat politics [Drachoussoff et al 1992 , Vol :2 $788 \mathrm{ff}]$. Agricultural production under the paternalistic supervision of the colonial agronomist came to govern the laborious working-day.

Although the colonial state had earlier tapped the indigenous labor force through notorious rubber campaigns, the imposition of cultures obligatoires quickly set new standards in terms of demands for labour force, agronomic innovations, economic organization and productivity. Daily life became almost completely centered upon agriculture. Ancient sacred institutions of leadership like the imbaa, who functioned among the Bombo as a judge and priest, were abolished, while other social institutions were reinforced as long as they served paternalistic tutelage. The exigencies of cash-crop production had their profound impact on the creation of a neo-traditional order within the village. The European agronomist had his indigenous counterpart represented by the moniteur agricole who supervised the details of cultivation. The head of the village, along with the village elders, was responsible for complying with the production quota of each household. Whipping and fines became an everyday occurence. We can assume that these "educative" measures failed among the Bombo as in the rest of Congo Belge [Jewsiewicky, 1983]. Nevertheless, some agronomic innovations should be kept in mind. They have survived and were modified by the local population resulting in a less intensive but nevertheless potentially effective form of shifting cultivation.

\section{COLONIHL INNOVATION AND POST-COLONHL ADRPTHTION IN SHEFING CULINYATION}

Pre-colonial agriculture was quite different from that practiced today. For the cultivation of the traditional staples bananas and yams only moderate clearings were needed, which were cut into the forest in the vicinity of the villages (see Fig. 2.1). These gardens were enlarged every year while old stands of bananas could remain up to five years. Shifting cultivation implied shifting the fields annually and moving the villages after 5-10 years. This became necessary when soil fertility declined, or the fields were too far away, or hygienic as well as strategic military options caused people to move. However, the cultivation of bananas ${ }^{(4)}$, the primary supplier of caloric food, was not at the center of economic activities. Reconstruction of the traditional economy of the Bombo revealed that hunting and collecting wild forest food was at least as important. Hunting methods of the Bombo, which included a wide array of trapping techniques designed to kill large game like elephants and buffalos and net hunting for antelopes, were in no way inferior to those 

tem was applied in the Ituri Forest ${ }^{(5)}$. It is questionable, to what extent suggestions of research stations, such as alternating strips of field and forest to ensure rapid forest regrowth [Tondeur, 1957], were put into practice. In most cases there was learning by doing. Over-exploitation of soil may have occured since length of fallow periods was unduly shortened. From local informants, who were functioning as moniteurs agricoles in the fifties, and current cultivation practice, one can conclude that, at least in the last colonial decade, crop rotation was as follows: first three years - Banana, rice banana/cassava; next two years-groundnuts, cotton.

Since cotton, groundnuts and rice were short-term crops that required 3-4 months of growth they could be easily integrated into existing practices of intercropping and field shifting. There was no need to introduce individual private ownership of land, as it was usually propagated in pajsannat politics especially to cultivate perennials like coffee. The corridor system respected communal land tenure, as land was redistributed to every household each year. This corresponded to traditional notions that land was the property of the patriclan or lineage, which distributed individual usufruct to its members. Only crops, not land, were individually owned. Resettlement nevertheless presented the problem that kinship groups became settled on the territory of others. In the Bombo community studied, which was founded in the early thirties by the association of two patriclans, one clan, whose territory was situated in the west of the village, came to settle on the territory of its neighbouring clan. This clan occupied the western part of the village and esta- blished their field corridor west of the village on their former territory. Until today each clan operates its own corridor (see Fig. 2.2).

From an agronomical point of view the corridor has many advantages. Pooling the fields of a village ensures a rational field-forest rotation with planned long fallows of 15 years and more (see Fig. 2.3). Agronomic supervision is relatively easy. The annual allotment of plots to the households is flexible and can be adjusted to actual labor capacity. Kinship-based patterns of land use and co-operation can be integrated. Annual movement of the corridor can be adjusted to variations in soil quality and the landscape [De Coene, 1956, Tondeur, 1957]. From the cultivator's point of view, however, things look different. A common field corridor is not flexible enough in terms of both labor allocation and social relations. At times the priority of long forest fallow causes unreasonably long walking distances from and to the villages. Although this is generally dealt with by building secondary huts in the fields, where the family can stay for longer periods of time, a certain portion of disfunctional households (see below) fail to allocate necessary labor to cut mature secondary forest or manage long transport distances. Lineage and patriclan solidarity set limits to individual decisions. Such group loyalty becomes a menace when conflicts arise within the larger community of the village.

The shape of the corridor today is different from its colonial forerunner in that it is shorter and more compact (see Fig. 2.4). Certain rules like the east-west orientation to use sun light more efficiently have been dropped. Arranging the fields in one long strip has been modified in 

tive to hide one's field from others. Moreover, the small corridor is more adaptable to the specific demands of the household. If someone is ill, one can cut young secondary forest and plant at least some cassava. The effect on forest regeneration is not necessarily negative, for secondary growth comes up rapidly, as fields are generally planted for one year only. Clearings are small and encircled by mature trees which seed secondary growth. If marketing opportunities should become better, cultivation of rice as cash crop could be intensified with little effort. The single corridor can be restored, if economic incentives override petty village affairs. For the present, however, priorities in organizing the field corridor have switched from economic and ecological requirements to social needs. The single corridor presupposes a degree of social harmony or consent the larger village community rarely can provide and it can be used as a source of social discrimination including witchcraft accusations, if crops fail on some fields while others are spared. The corridor system, as it exists today, reflects these social constraints.

\section{CULIIVATION CYCLE}

Just like the corridor system, the cultivation cycle has been adapted to local conditions. Following the colonial innovations, crop rotation represents a mix of the non-seasonal perennials, bananas and cassava, and the seasonal annuals, groundnuts and rice. The former can be planted and harvested at any time of the year. The latter deserve proper timing to make optimal use of seasonal rainfall (see Fig. 3). Together with cotton, groundnuts and rice have come to determine the cultivation cycle under colonial supervision. Although their importance as cash crops is continually declining (cotton cultivation has been abandoned completely), they still govern the agricultural work calendar (see Fig. 4).

Men begin forest clearance in October/November. After measuring the fields, the undergrowth is removed with the machete, work which is usually done cooperatively by neighbours. Then trees are felled with axes, arduous work that continues for weeks with breaks of some days. Vegetation is not removed completely. Particular hard wood species are left standing. Clearing should be finished in January, so that felled vegetation will be dry enough to be burned in the middle of February at the peak of the dry season. Further cutting and burning of logs and trunks is carried out later, as pieces of land are prepared for planting. The first bananas and cassava can be planted in the new field as soon as the underbrush has been cut. Subsequent buming does not harm shoots or larger plants. Groundnuts are sown March/April and harvested June/July. Land is weeded and burned before rice is planted in June to August, to be harvested from November to February. High amounts of rainfall over nine months of the year generally provide considerable latitude in the timing of activities, and there are variations of up to three months in planting and harvesting dates of groundnuts and rice. Nevertheless, yields can vary according to rainfall, damage inflicted by game, and labor input. In a sample of 4 particularily productive fields the yields of three staple crops could be calculated: medium yields of rice were 1,640 $\mathrm{kg} / \mathrm{ha}$, of hananas $6,150 \mathrm{~kg} / \mathrm{ha}$ and of cassava $5,100 \mathrm{~kg} / \mathrm{ha}$ [Rösler, 1997]. 



\section{INSTITUTIONAL CONSTAPHNTS OF DOMESTIC PRODUCTIOH}

In the agricultural season of $1986 / 8762 \%$ of households in the village studied were not self-sufficient and in 1987/88, 72\%, though they were dependent upon agricultural production and had no significant alternative source of income. In 1986/8730\% of housholds were self-sufficient and only $8 \%$ were surplus-producers. In the following year, $28 \%$ were self-provisioning and there were no surplus-producers at al! ${ }^{[6]}$. The primary reason for such low agricultural productivity is that a considerable proportion of housholds are disfunctional. As a rule households are monogamous nuclear families, with a medium size of 3.8 persons. They are thus particularily fragile production units vulnerable to shortage of personel. In 1986/87 30\% and in $1987 / 8844 \%$ of the households were underproductive due to death or illness of one of their members or because the couple divorced or separated (the latter being the case particularily with young couples, who live together before bridewealth is paid). Any household can experience such a situation from time to time. If cases of domestic underproduction accumulate they can result in chronic local food shortage.

The majority of households, however, can be considered as consolidated and functional, as they are based on marriages sanctioned by payment of bridewealth and have at least two able-bodied adults at their disposal. Nevertheless about $45 \%$ of these households are underproductive as well (accounting for $32 \%$ of the total number of households in 1986/87 and for $28 \%$ in 1987/88). The reasons for this vary. All households, including underproductive as well as self-suppliers and sur- plus-producers, face one or more of the following internal and external constraints on agricultural production.

1. Ahsence of women from hushand's household. This is a function of the inferior social status of women in the patri-virilocal context. In the village of their husband women are treated as "strangers", who are not allowed to participate in decisions of the communal hut of the local patrilineage. Emotional bonds of women to their own natal lineage remain strong, resulting in frequent visits to the village where they were born (see Fig. 5). These can reduce the wife's labor input in the fields of the husband's household. Long absence of wives sometimes results in complete abandonment of a field.

2. Conflicts over the sexual division of labor. Although agricultural labor input is moderate and differences between the sexes are not strongly pronounced (see Fig. 5$)^{[7]}$, the latter give rise to conflicts about the responsibility for certain timeconsuming tasks like weeding. Whereas these were performed under colonial supervision by men and women in co-operation, today they are left almost completely to the women which leads to a bottleneck in the case of rice planting.

3. Iack of cash economy. Only a small fraction of the rice harvest of 1986/87 was sold to official byers. In the next year there was a complete breakdown of agricultural marketing due to the restrictive price policy of the government. Most of the surplus-producers refused to sell their crop. Moreover, the status of rice as potential cash crop has resulted in different opinions within the household about who is the owner of the crop. Women should receive their shares when the crop is sold, 



mercial agriculture and no meat trading as in other parts of the Ituri [Hart, 1978], no conflicts arise about the distribution of the earnings - the Bambuti being part of the larger community of relatives who all claim their share. On the other hand, where commerce arises, Bambuti are apt to adapt more rapidly [Ichikawa, 1991]. Low agricultural performance of their former patrons is possibly related to their readiness to look for other exchange partners.

\section{THE LOCAL AGRICULTURE IN PEASPECTIVE: ADAPTATION TO THE INFORMAL SECTOR}

Agricultural production in the Ituri forest is on the retreat. The ongoing Zairian crisis and disorder creates considerable insecurity and intimidation among the rural population. As in other parts of the country [Schatzberg, 1988], the people of the Ituri Forest react by opting for exit: in order to reduce losses due to governmental and military seizures, they limit cultivation to mere subsistence necessities, at times leaving their villages and hiding in the forest, occupying temporary forest camps they traditionally used for hunting and fishing, and which today are suitable for gold-digging. By doing this they renew ancient customs, which fell into disuse only in colonial times. Since the semi-nomadic way of life is not restricted to Mbuti and other Pygmies alone, and since the overall political and economic situation of the country does not offer an integration into a broader cash economy, it is worth considering some local institutions in terms of their adaptive function within the context of political insecurity, economic decline and the possible ecological degradation of the forest that is yet to come.
The Ituri has one of the lowest population densities in Central Africa. It borders on nearby savannah and mountainous areas, with the highest population densities in the country [Wiese, 1980: Map 7]. The pace-makers of future development will stem from these areas, and the indigenous people of the Ituri, either villagers or Pygmies, will have no say in this matter. Traders of Beni and Butembo already hold key positions in commerce. As the state structure rapidly declined in the last decade, informal economy has taken over. The northern Kivu, ethnically dominated by Wanande, became a booming center of more or less illegal commercial activities, including smuggling from and to Uganda, Kenya, and the Sudan [Vwakyanakazi, 1991]. The Ituri Forest constitutes the hinterland of this informal sector. It functions as a reserve of forest resources like ivory, hides, gold and timber. Information on how far local people have already become involved in these activitites is scarce.

At least some current studies of Mbuti Pygmies suggest that the commercial meat trade to serve the Kivu town markets has resulted in depletion of game and endangers Mbuti subsistence needs [Hart, 1978]. In the northwestern corner around Wamba, Mbuti are supposed to have "hunted out" the forest [Wrhle, 1986]. As Mbuti become involved in a cash economy they are not used to, they are ridiculed and treated as fools by village people [Ichikawa, 1991]. At the same time low agricultural performance seems to be causing Mbuti to dissolve former patronclient relations in favor of new more spontaneous commercial relations. The opposition of "village world" and "forest world", as reported by Turn- 
bull $(1965,1983)$, was confined to a few commercial centers like Epulu in the sixties. It is now becoming the scenario for future development under frontier conditions.

The Bombo, situated in the inner Ituri Forest, as well as the Bambuti associated with them, are not yet involved in either frontier or informal activities. For them the situation is different and poses other problems. The expansion of informal commercial activities is confined to the gold sector. The carriere is integrated in their normal seasonal activities including semi-nomadic camping in the forest either for fishing or hunting and/or gold-digging. Bambuti may serve carrières and meat traders occasionally showing up with smoked antelope meat. Bombo, if they do not dig for gold themselves, supply carrières with fish and manufactured produces like pirogues. In general this trade is moderate. Along the banks of the western Ituri Lokele fishermen from Kisangani have settled and some disputes over fishing rights and competition in trade occur, but interethnic relations are not strained. Occasionally, poachers, who are said to be deserted soldiers armed with army guns, present dangerous foes in the forest and some remote villages. There is a rumor among Bombo that Pygmies of Lombi, who live farther off towards Kisangani, defend their hunting grounds against intruders with poisoned arrows, though this sounds like wishful thinking. When soldiers show up in the villages, the population usually does not dare to raise its voice, let alone to take any action.

Although the carrière does not offer great prospects, it will be the economic focus of the years to come. As alluvial gold deposits do not suffice to make a man rich, the golddigger's camp serves as a decent source of income, either by the direct revenue from washing gold or by selling small amounts of local produce. The informal sector does not demand agricultural products from the Ituri, for they can be more easily supplied by the fertile areas of the Kivu. The agricultural system of the forest, though based on agronomically improved field-forest rotation and intercropping, is currently underused. It can serve local subsistence demands, but it is questionable whether it will ever significantly contribute to the national or regional economy. While corresponding to current notions of sustainable development in terms of marketable surplus production and forest conservation granted by long-fallow shifting cultivation [Hunter and Ntiri 1978], it cannot compete with the more productive agriculture of the mountains. Moreover, it is questionable whether it will be accepted by new settlers, who often cling to accustomed food preferences and agricultural practices ${ }^{[\theta]}$.

Commercial agriculture, coffee and oil plantations, are rare in the Ituri Forest. As far as they are remnants of colonial enterprises, they are of minor importance. Immigration from the Kivu is accompanied by setting up plantations of beer bananas. The ecological effect is not yet clear. Agricultural intensification has been going on for decades around semi-urban centers, and forest cover has been removed over vast areas. Local practices of shifting cultivation are surely not adapted to this situation. It has never been examined, whether agronomic improvements have been developed spontaneously by the local urban population. Agricultural produce coming from the villages like 
rice could surely serve these urban markets, but a noteworthy market system did not develop under colonial rule and was not supported in post-colonial times. Towns are largely supplied by Kivu products. Local agriculture is once again not in demand.

Summing up one can state a paradox: although from a technical point of view there is a locally and ecologically well adapted agricultural system, based on agronomically improved shifting cultivation that could potentially integrate forest conservation and agricultural production, the system is badly underused and on the verge of disappearing. What developmental experts may still conceptualize is already there, but nobody practices it, since the developmental issue from the peasant's point of view has become a question of hiding or concealing their crop from the state and the military, and at times even from their nearest neighbours.

\section{ENDMOTE}

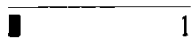

I am grateful to Werner Petermann, Johannes W. Raum and Polly Wiessner for their critical comments orl a preliminary draft.

\section{2}

For a lengthy discussion of the implications for hunter-gatherer research in the Ituri see Rösler (1992).

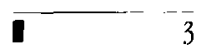

Indigenous expressions given in Kingwana, the regional Swahili dialect, that is widely used as vernacular in interethnic discourse.

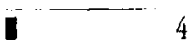

These are mostly plantains designated by the Bonbo with the generic term $i b u g u$, of which they still cultivate 15 varieties.

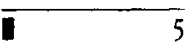

Drachoussoff et al. (1992, vol, $2: 799$ ff), contains more detailed information.

\section{- 6}

Sample size was 50 households with a total of 190 individuals. Household proluctivity was calculated in tems of caloric needs of household members. Surplus is defined as output exceding household needs by more than $25 \%$ (Rösler, 1997).

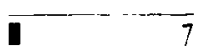

Time allocation data were gathered in 36 village households over 12 months in 1988 using the random visit method of Johnson (1975). The sample includes data on the daily activities only of adults (Rösler, 1997).

\section{0}

For example, Alur cultivators coming far from the upper Blue Mountains and settling at the central road could be observed cultivating cassava with short fallow of five years and extending the cultivation period of the field to three years. This practice was taken over from the mountains, where soils are much more fertile. In the forest this will deplete the capacity of the soils to recover and ultimately remove secondary forest in favour of bush vegetation and stands of Imperala. This may be instructive of how food preferences (not population density or land scarcity) deternine cultivation intensity.

\section{LEGENDS OF FOTOS}

I : Forest clearance: Bambuti men assist in cutting trees on the field of their village patron.

¿ : Secondary settlument (malende) of village and Bambuti households.

3 : Forest clearance: a field corridor cut into a mixed stand of primary and mature secondary forest.

4 : Wanande immigrants panning gold at the bank of the Ituri river. 